\title{
From spiral to helical stairs: Santa Cruz la Real and Santiago Apóstol approaches
}

\author{
P. Benítez, \& M. Valiente \\ Universidad Politécnica, Madrid, Spain
}

\begin{abstract}
In the late $15^{\text {th }}$ and the early $16^{\text {th }}$ centuries different styles coexisted in Spain Amongst them , the predominant one was the late Gothic Architecture. This paper focuses on the helical staircase as one of the more representative elements of this style. It analyses the geometric and constructive configuration of (i) the stair located in the church apse of the Monasterio de Santa Cruz la Real in Segovia and (ii) the one located in the tower of the Santiago Apóstol Church in Villa del Prado. As will be shown, both are examples of seemingly intermediate steps between the spiral and the helical staircases. Our purpose, is to contribute to the knowledge about the way this type of circular staircases were built and gain a better understanding of the process followed by the stonemasonry masters. Both aspects are essential to provide a solid foundation for the preservation of this type of Heritage.
\end{abstract}

\section{INTRODUCTION}

The processes of restoration and preservation of Heritage elements is frequently characterized by a lack of understanding how these elements were constructed together with the ignorance of their background. These result in an incorrect diagnosis of their defects and in inappropriate solutions and conservation proposals.

Particularly, regarding circular staircases of the late Gothic, this problem usually gets worse. Their hidden location inside the masonry walls, which meant a difficult access, their small size, their utilitarian nature, and the lack of written references other than outlines in the general building plans, have impeded the research on this type of stairs. Nevertheless, in order to carry out a correct preservation plan it is essential to get in depth in their constructive and structural aspects and processes.

Our purpose is to contribute to the knowledge about the way this type of circular staircases were built and gain a better understanding of the process followed by the stonemasonry masters. Both aspects are essential to provide a solid foundation for the preservation of this type of Heritage.

More specifically, in this paper we focus on two spiral staircases that are not detailed in any of the early Spanish treatises that refer to circular stairs. This work analyses the geometrical, constructive and structural configuration of (i) the helical stair located in the south wall of the new church apse of the monastery of Santa Cruz la Real in Segovia and (ii) the one located in the tower of the Santiago Apóstol Church in Villa del Prado.

We will show that these two stairs follow an unusual pattern compared to other stairs of the same period. Thus, any contribution to their analysis might also help to any future restoration and preservation process on them. Finally, we address the effect of the design on the stability in both cases, focusing on the Santa Cruz one, since it is currently in a ruinous state. We will discuss whether the design has played a part in its current state.

\section{GEOMETRICAL AND CONSTRUCTIVE CONFIGURATIONS}




\subsection{The staircase of the monastery of de Santa Cruz la Real}

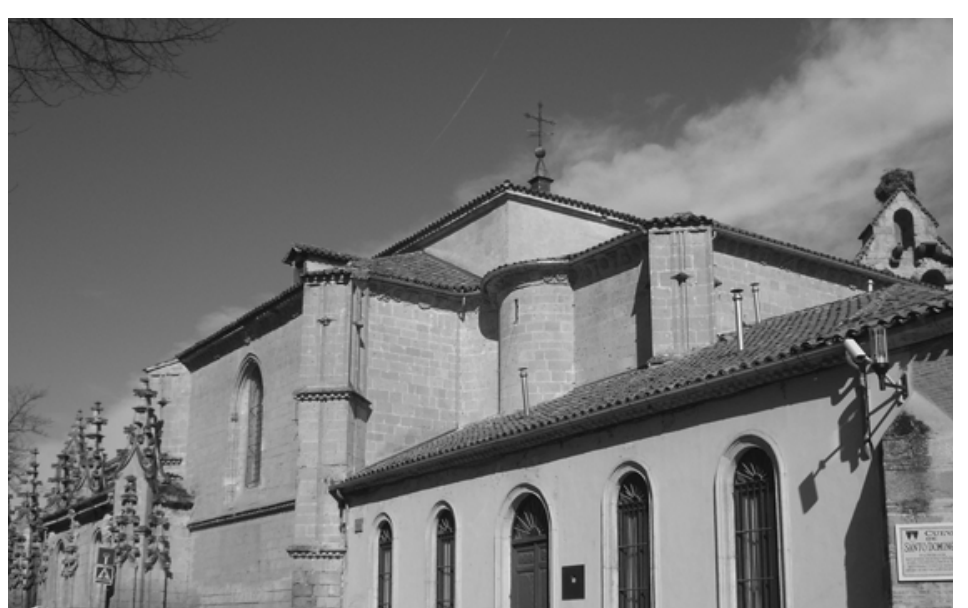

Figure 1 Church of the monastery of Santa Cruz la real. From left to right: staircase cylinder, apse and bell-gable. (Photograph by P. Benítez)

The Monastery of Santa Cruz la Real is located in Segovia, outside its city wall near the Eresma River. It was founded by Saint Dominic in 1218 and rebuilt by order of the Catholic Monarchs in the late fifteenth century. Its reconstruction was according to plans of master Juan Guas, whose work in the monastery from 1478 until 1492, is known thanks to the Account Books of the construction of the Cathedral of Segovia. The construction project meant the construction of the late Gothic church as well as its main facade among some other works.

Although many masters took part in the church construction, the apse and transept walls were planned without any doubt by J. Guas (Carrero, 1999). Since the studied staircase is situated in the south wall of the apse, it is evident that it was also planned by him in the period he was working on the convent between 1478 and 1492. The staircase ascends to the church attic, in order to reach the monastery bell-gable. An arch doorway that is hidden behind the altarpiece gives access to a first straight flight with a total of eight steps. It leads to the circular stair that is being studied. After a bibliography research, no written reference has been found about it, but its outline in the general plan of the monastery complex. Therefore, we have directly analyzed the staircase obtaining and measuring all its key dimensions (by ordinary means as tapeline and photographs).

The stair is inscribed in a cylinder with $180 \mathrm{~cm}$ in diameter which in turn is attached to the wall apse and is visible from the outside even though it is half-buried (Figure1). Following a circular geometry solution, the stair has been shaped by a stone step turning around a central axis. In this case the newel is not vertical but helical and runs tangent to a small central hollow. Originally the stair had a total of sixty four steps. Nowadays it is in a very poor condition and only the first six steps at the bottom landing and eight steps at the end remain. The others have been replaced by timber steps which form a spiral stair with an evident provisional character. The last eight-step flight that remains is not usually treaded because the access to the attic is in the fifty eighth step, which is the last added timber one.

A full turn requires fourteen steps to be completed. Each step rests on the one just below and is embedded in the exterior stair wall. They have a circular wedge shape that does not point to the geometrical center of the stair. Instead, it goes tangent to the hollow. The tread has a $45 \mathrm{~cm}$ long chord next to the wall and it narrows until it turns into an apex in the inner part. The unit riser is $20 \mathrm{~cm}$ high (Figure 2). As we will see, this feature makes this Gothic helical staircase a significant example as this step module was not commonly used.

The intrados is a smooth helical surface that determines $280 \mathrm{~cm}$ of headroom all along the stairway. A handrail is carved in the exterior wall $83 \mathrm{~cm}$ above the tread. It continues until the church attic, although it is interrupted once to form a door frame molding, which seems to give access to a church inside gallery. After analyzing the interior masonry walls of the crossing and 
apse, no signs of any entrance could be detected. There is also another handrail that runs along the central hollow, which is formed by the molding that finishes each step piece.

There are only two small openings in the wall, which let in the light, although they are obviously not enough to illuminate the stairway. Both windows have a splayed rectangular section. The first one, at the bottom landing level, is closed off with stones. In fact, it opened to the inside of a later construction, which was built onto the church wall. (Nowadays it is used as student residence hall). The other splayed window is opened in the last eight-step flight that still remains. Its section was narrowed, probably to avoid pigeons to come in. Therefore it is a dimly lit stairway with an important lack of natural light.

The staircase as the entire church was built up with limestone extracted from quarries located only a few kilometers away from Segovia. The limestone types used are Parral Stone and Bernuy limestone. The Parral Stone is a fine grain limestone, yellowish cream-colored and rosier than the Bernuy limestone.

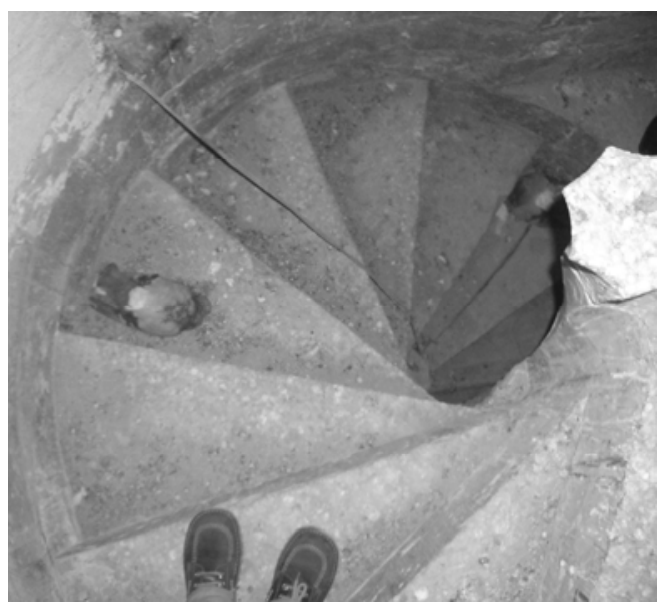

Figure 2 Last eight steps-flight of the staircase of Santa Cruz. (Photograph by P. Benítez)

\subsection{The staircase of Santiago Apóstol church}

The parish church of Santiago Apóstol is located in Villa del Prado main square. It is a village at the south east area of Comunidad de Madrid and near Toledo. Its construction took place from the late fifteenth up to the mid- sixteenth century, therefore the transition from the late Gothic to the Renaissance can be appreciated. The building has two towers: (i) the older one of Gothic style that is finished with a bell-gable; and (ii) the Tolosa tower with an obvious renaissance influence. The last one contains the stair that is aim of this study (Figure3).

The tower is detached to the north east side of the church. It has $10 \mathrm{mx} 10 \mathrm{~m}$ square plan and is $30 \mathrm{~m}$ high that is divided into 3 sections. During its construction, many masters took part in it due to the frequent economic problems. According to the Account Books of the church construction, the tower was designed by Juan Campero around 1544. He was an important master who worked in Segovia in the construction of many relevant buildings like the monastery of El Parral and the moving the cloister of the Saint Mary old Cathedral, designed by master Guas, to its actual location. Ochoa de Muniategui helped him with the building works of the first section of the tower (Marías, 1986). Another important figure was Pedro de Tolosa, master mason of El Escorial. He resumed the works and raised the second section of the tower following the design of Muniategui, according to the duties settlement that is kept in the parish archive. Another important figure was Pedro de Tolosa, master mason of El Escorial, who restarted the works and raised the second tower section following the design of Muniategui as it is written in the duties settlement that is kept in the parish archive. The tower was finished by the master Lorenzo in the late sixteenth century, following the last design of Hernán González de Lara. The Account Books just indicates the name of the master who finished the tower, Lorenzo, not including any additional data about him. Moreover, in the literature, there are no further references about this person or any of his works. Finally in the 1990s the lack of maintenance motivated its restoration, whose author was the architect Riaño Lozano. 


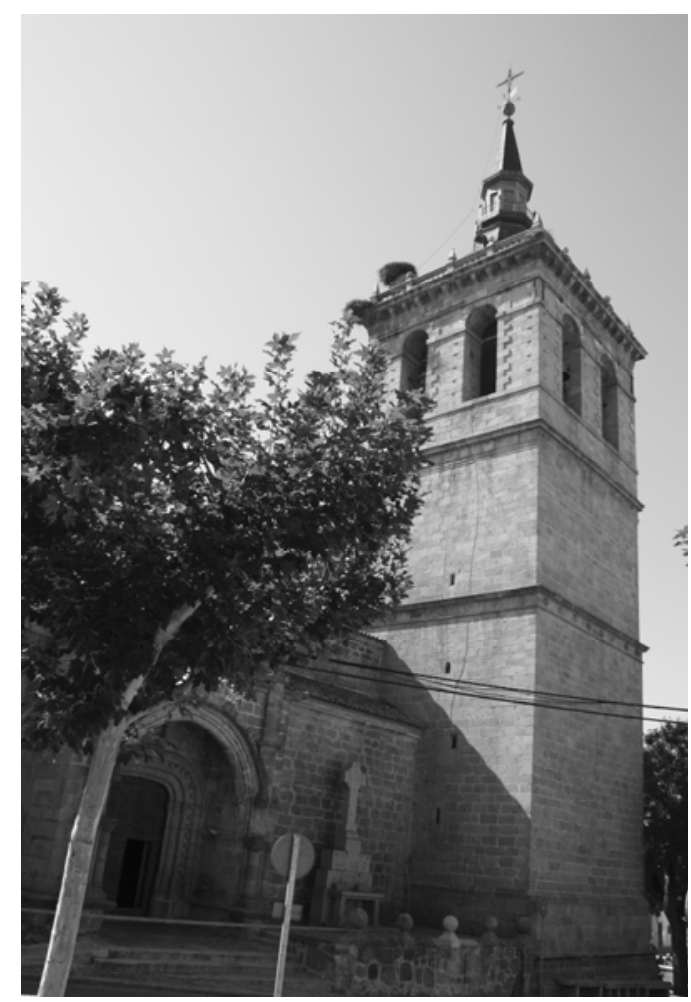

Figure 3 The tower of Tolosa. Santiago Apóstol church. (Photograph by P. Benítez)

Although the tower has an obvious Renaissance appearance, some late Gothic architectonic elements can also be found, as the staircase under study that runs it through. The entrance of this stair is located at the northeast of the church and it is divided in four flights.

The first one runs through the first section of the tower and gives access to different rooms. Its solution corresponds to an anticlockwise helical stair. It is inscribed in a cylinder with 155 $\mathrm{cm}$ in diameter hidden within the thickness of the east tower wall, except in the second room where its volume can be seen. Twelve steps complete each turn. The intrados is a helical surface except in the last ten ones where a light belly can be observed in each of them. Each step is 65 $\mathrm{cm}$ wide. Its tread has a $46 \mathrm{~cm}$ long chord next to the wall and it narrows to $12 \mathrm{~cm}$ in the inner part which is finished with a molding. And its riser is $20 \mathrm{~cm}$ high.

The second flight is straight and $85 \mathrm{~cm}$ wide with a total of 9 steps. Each of them has a tread depth that ranges from 30 to $35 \mathrm{~cm}$ and a riser height of $20 \mathrm{~cm}$.

The third flight is the more interesting one. It is located in the southeast corner of the tower and gives access to the bells group room. It is a stair with a simple circular plan that at the first glance looks like a traditional spiral stair. It is inscribed in a small cylinder of $130 \mathrm{~cm}$ in diameter that is only visible from the same room as the first flight. It turns clockwise and has twelve steps in every turn. The trasdos surface of the first three steps is helical, but from there on remains stepped. The feature we want to point out is that the traditional central newel that begins at the seventh step is not vertical. It slightly deviates from the central axis until the twentyseventh step where the newel goes back to the central axis again. Each step is $68 \mathrm{~cm}$ wide. Its tread has a $35 \mathrm{~cm}$ long chord next to the wall which narrows until it turns into an apex in the inner part. Its riser height is $20 \mathrm{~cm}$. From the bells group room on, a last flight give access to the flat roof of the tower. It is solved by using a traditional spiral staircase that is inscribed in a cylinder with the same dimension as the previous one (Figure 4)

A metallic handrail of circular cross-section fixed to the wall runs all along the stair. As the Santa Cruz stair, it is a poorly lit stairway with an important lack of natural light.

The staircase as the entire church was built up with granite extracted from the nearby quarries. 


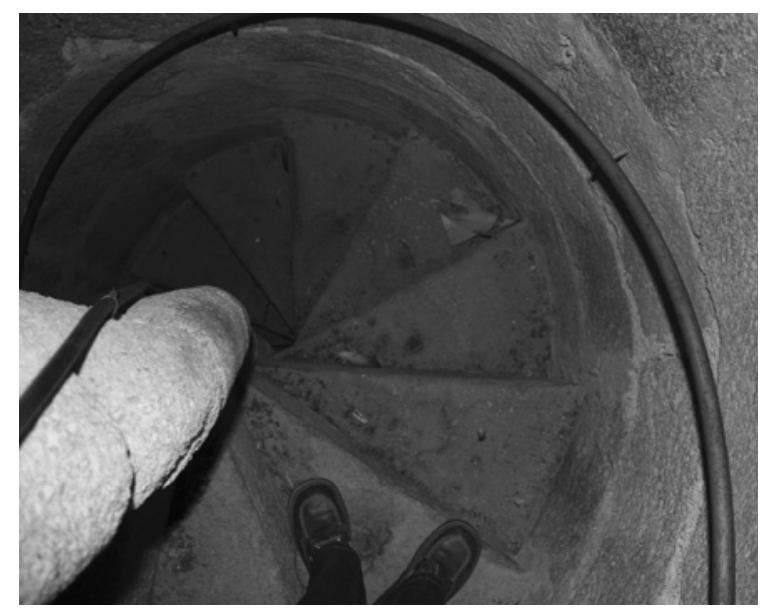

Figure 4 Staircase of Santiago Apóstol Church. (Photograph by P. Benítez)

\section{STABILITY ANALYSIS: ORIGIN OF PROPORTION RULES}

Having studied the geometrical and constructive configuration of both stairs, it is necessary the analysis of their stability since it is a fundamental criterion in designing this kind of stone masonry element. According to the traditional method followed by mason masters, the stability is ensured by geometrical criteria which define the relationships between shapes and sizes of the different parts of the stair. That is to say, the way the masters ensured the stability of a stone structure consisted in choosing the right shape (Heyman, 2004). If the element shape does not change, the original secure stability is guaranteed.

As sources for proportion rules, masters had the building practice as well as the direct observation of examples already built or detailed in the stonemasonry treatises (Heyman, 1999). Therefore, the proposed methodology for this research includes the comparative analysis of the stairs of Santa Cruz and Villa del Prado with stairs described in the early Spanish stonemasonry texts and with a few samples built around the same period. Our aim is to check whether the design patterns of the stairs of Santa Cruz and Villa del Prado were used or repeated in other late Gothic circular stairs.

\subsection{The early Spanish stonemasonry texts}

The first stonemasonry texts appeared in Spain by the end of the sixteenth c. and the beginning of the seventeenth century. These texts are handbooks that collect solutions to common geometrical problems that may occur during construction. They permit other master builders its correct reproduction. Thus, the early texts of Vandelvira, Martínez de Aranda, Gelabert, Portor y Castro and Berruguilla which detail the geometrical description of both circular stairs, the spiral and the helical (Sanjurjo, 2007), have been used as a comparative reference.

After their analysis, it was noted that all of them describe models of similar features. They all depict circular staircases, spiral or helical, as a structure with geometry of revolution where the step rotates around a central axis to shape the stair. The first common feature we want to point out is that in all of the stairs analyzed, the longitudinal edges of the step riser matches up with the radius of the staircase circumference. In all cases this edge is directed towards the centre of the case. The second common feature for all the analyzed stairs is that the length of the step piece never exceeds the radius length. In the helical stair, the central hollow appears when the pole of its corresponding spiral stair case is removed and replaced by space that means that, the step cuts its length to generate the central hollow (Figure 5). 

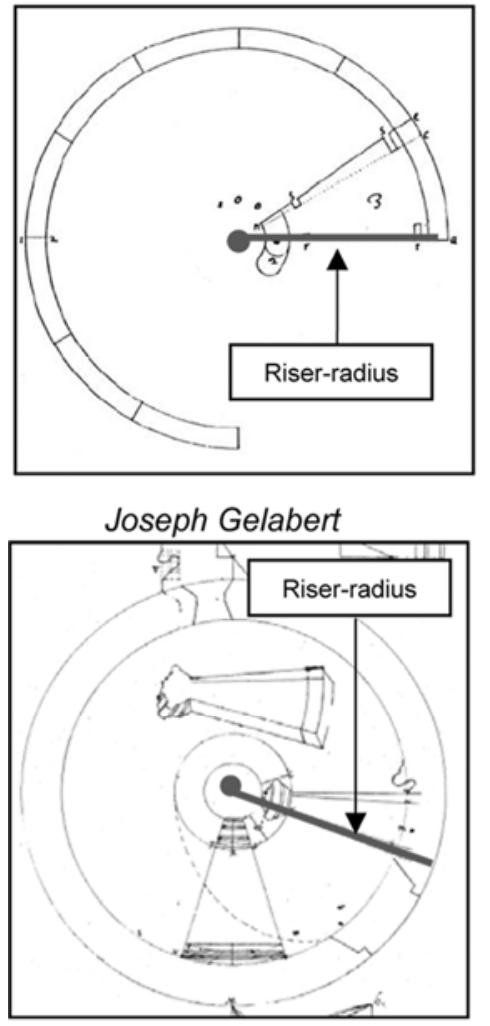

Alonso de Vandelvira

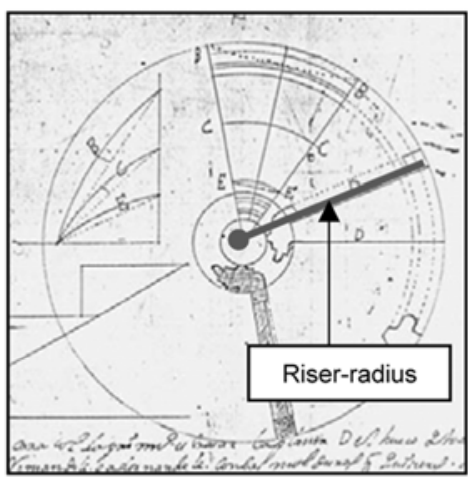

Juan de Portor

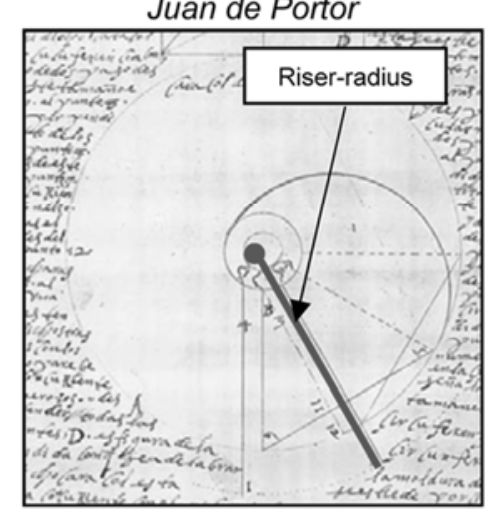

Alonso de Guardia

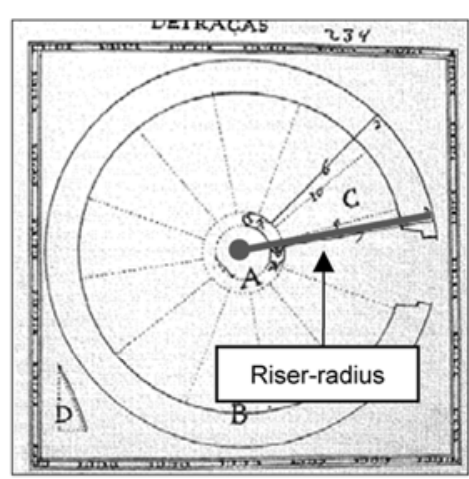

Ginés Martínez de Aranda.

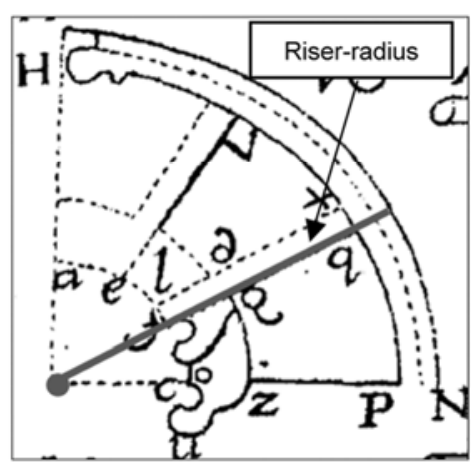

Juan García de Berruquilla.

Figure 5 Helical staircases defined in the early Spanish treatises. (Drawing by P. Benítez)

In order to compare the design of the stairs under study with the solutions proposed in the treatises, the Santa Cruz and the Villa del Prado design patterns were superimposed on the treatises drawings. As was expected, it revealed that none of them matched the stairs described in the texts.

Regarding the step-module, what attracts our attention is that the step piece of both studied stairs has not a radial riser. On the contrary, it is traced tangent to the central newel in the Villa del Prado case and to the central hollow in the Santa Cruz case. Both stairs use a fan-stepmodule (Carreiro, 2007) in contrast to the sector-step-module used in all circular stairs described in the early stonemasonry texts. And this necessarily implies that the step must be longer than the radius of the staircase circumference. This feature is really original with respect to those contained in the first Spanish treatises, and is the key characteristic that makes these staircases so different from the other ones.

In the case of Villa del Prado, the similarity to the spiral stair is obvious. We can see how its central newel is not vertical and slightly deviates from the central axis. Although it could be considered as a carving mistake, it is not since each step piece perfectly fits one over another. This is due to the fact that the step piece is longer than the radius of the circumference of the staircase. Nevertheless, in this case, the step is not long enough to generate the inner hollow which is essential to get a better illumination and to improve the circulation of people inside the stair, both basic features of the helical stair. Due to these characteristics, and with the intention of distinguishing between the traditional spiral staircase and this one, it was recently classified with the new name of "husillo de machón helicoidal" (spiral staircase with helical newel) (Sanjurjo, 2013).

In the case of Santa Cruz stair, a small inner hollow appears in the staircase center as well as a richer decoration consisting of a carved handrail on the exterior wall and a molded handrail that runs around the hollow. This stair fulfills the following requirements to be considered as a helical staircase:

- A step-module revolves around a vertical axis generating the staircase; 
- A central hollow allows a better illumination of the space and facilitates the movement of persons (Palladio 1570);

- The central pole is still present, but it is not located in the center of the staircase but surrounds it. (Calvo 2000).

- This staircase has not only a functional purpose like the spiral one had, but also some decorative value.

The solution proposed to form the inner hollow helical stair of Santa Cruz is the most original contribution with respect to the traditional ones described in the treatises. In the stonemasonry texts, as we have already explained, the hollow materializes when the a sector-step-module cuts its length. However, in the Santa Cruz staircase the procedure is by a fan-step-module longer than the radius and with a step riser which goes tangent to the inner hollow. In general, the longer the fan-step-module is, the larger becomes the central hollow. And the other way round, the larger hollow is needed, the longer fan-step-module must be.

Santa Cruz stair breaks with the traditional construction as the Villa del Prado stair does. Both are unusual solutions for circular plan stairs that do not follow any generic pattern described in the treatises and share the same generative principle: a fan-step-module. However, there are significant differences among them: the existence of the central hollow and the richer decoration of its newel. Thus, we propose to classify it differently to the Villa del Prado stair. Santa Cruz stair is a "helical staircase with a tangent solution" instead of the usual "helical staircase with the radial solution". In our opinion, the solution proposed in the Santa Cruz stair is a valid way to solve the helical stairs, but it did not achieve a widespread use.

\subsection{Other real built examples}

As mentioned above, the proposed methodology for this research includes the comparative analysis of a few samples as another source of the proportion rules. The brief survey includes stairs which have been chosen according to various criteria: location (Spain), its constructive solution (helical stairs) and scale (small-scale stairs), chronology (late Gothic), belonging to a significant building, and easy accessibility to the stairs in order to permit a direct observation.

According to this, the following examples have been studied: Merchants Market of Palma in Mallorca which is the first helical staircase in Spain and origin of the name "Mallorca staircase" also used in Spain for the helical stair; Ancient Silk Market of Valencia which is the first example of helical stair in the Iberian Peninsula; the new Cathedral of Salamanca which was designed by Gil de Hontañón, master who generalized the use of helical staircases; Fonseca Residence Hall in Salamanca which was designed by Diego de Siloé and built by Gil de Hontañón; monastery of Santa Cruz la Real in Segovia which is aim of this study; Villa del Prado which is also aim of this study.

One of the results of this analysis has been a set of data sheets, one for each example, which compiles its most relevant characteristics. We detected that all them except the stairs of Santa Cruz and Villa del Prado use a sector-step-module where the riser-longitudinal-edge point to the geometrical center. We also could appreciate that they solve the central hollow when the sectorstep-module cut its length.

This analysis shows again that Santa Cruz and Villa del Prado have a design that solves the spiral and helical stairs in an unusual way.

\subsection{Structure stability analysis}

Once the original geometrical solution of both staircases has been confirmed, we have studied how their design can contribute to its stability.

In Villa del Prado staircase, once the danger period of twenty years (Heyman, 1995) has been largely exceeded, its stability has been assessed and therefore its correct geometrical solution. The same cannot be said of Santa Cruz staircase, whose design is called into question by its current ruinous state. In order to check if the geometrical pattern caused its instability, we conducted a study based on the traditional method used by the stonemasonry masters. With the intention of solving constructive problems, the Gothic masters usually used small scale-models of the architectural element they wanted to check. If the model kept its stability, masters set the key 
dimensions of the different parts of the real element by the proportion rules given by the model (Heyman, 2004). Thus, we built a 1:10 scale model of the Santa Cruz staircase in order to verify its stability and get a better understanding of its construction through the movement of the step piece around the central axis.

The model was built by using the latest digital technologies in the "Numeric Design Lab" (NuDL) at IE University: a laser cutting equipment of numerical control (Versalaser of Universal Laser System), which is digital method commonly used in the architectural design today. It provided the high accuracy needed for the perfect geometrical definition of each section of the step piece including the bend-radius of the handrail molding that surrounds the staircase hollow. The scale model reproduced the fourteen steps which complete a full turn. It was made of MDF boards of 3mm thick. This material was chosen because it is easy to handle and affordable (Benítez, 2013)

The model showed the structural stability of the Santa Cruz staircase and assessed that it would be possible the construction at real size of a stonemasonry staircase provided the proportion rules are fulfilled (Figure 6).

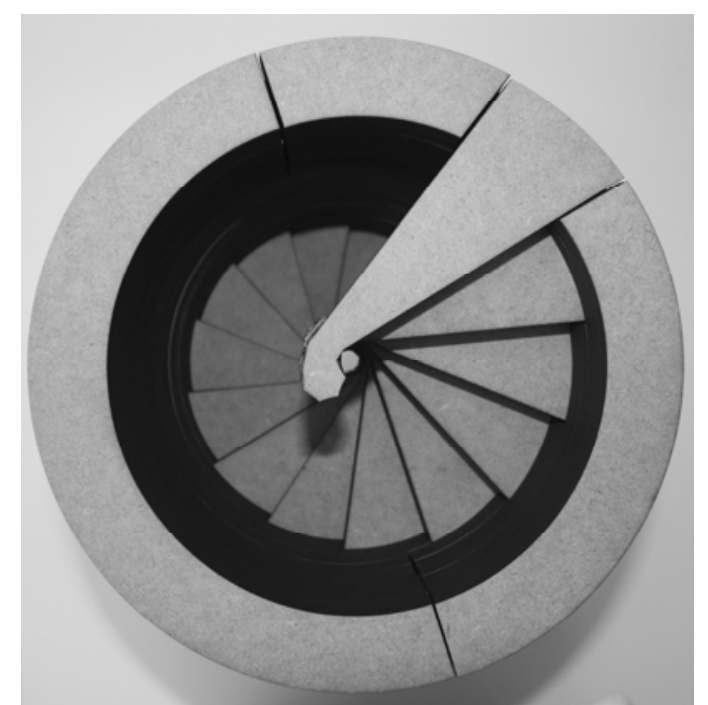

Figure 6. Scale-model of Santa Cruz staircase (Photograph by P. Benítez)

\section{CONCLUSIONS}

In this paper we have analyzed the geometrical, constructive and structural configuration of the circular staircases located in the church apse of the Monasterio de Santa Cruz la Real in Segovia and the one located in the tower of the Santiago Apóstol Church in Villa del Prado. These stairs were built in the late Gothic style and are examples one of the more representative elements that is staircase with a circular plan, the spiral and the helical ones. The studied examples were designed by important masters of that period. With the aim of solving a common problem of circulation within the building, and at the same time having in mind the search for innovation, these masters did not follow the traditional design for this type of stairs.

The methodology we have followed has been based on a comparative analysis with stairs described in the early Spanish stonemasonry texts and with a few samples built around the same period. As a result of the analysis, we can conclude that both have a similar design based on a new unusual step module. This significant variation with respect to other contemporary stairs has led to classify the Villa del Prado stair recently with the new name of "husillo de machón helicoidal” (spiral staircase with helical newel). Regarding the Santa Cruz staircase, it presents additional variations in its design to solve the inner hollow of a helical stair through a fan-stepmodule and a richer decoration of its newel. Thus, we have proposed a different classification for this star as "helical staircase with a tangent solution" instead of the usual "helical staircase with the radial solution". In our opinion, the solution proposed in the Santa Cruz stair is a valid way to solve the helical stairs, but it did not achieve a widespread use. 
Finally, we have addressed the structural stability of the stairs. In Villa del Prado staircase, the danger period of twenty years has been largely exceeded, thus its stability has been assessed. On the contrary, Santa Cruz stair is currently in a ruinous state. Thus, we have conducted a study based on the traditional method used by the stonemasonry masters in order to assess its stability. As a result, a 1:10 scale model has been built showing the required stability. Therefore, we can conclude that the solution of the Santa Cruz staircase is a valid one from the stability criterion.

\section{REFERENCES}

Benítez, P. 2013. Diseño y construcción del caracol de mallorca de la iglesia del monasterio de Santa Cruz la Real (Segovia). Octavo Congreso Nacional de Historia de la Construcción. Madrid: Instituto Juan de Herrera

Calvo López, J. 2000. Cerramientos y trazas de montea de Ginés Martínez de Aranda. Tesis Doctoral. Madrid: Universidad Politécnica de Madrid

Carreiro, M. 2007. El pliegue complejo. La escalera. La Coruña:Netbiblo

Carrero Santamaría, E. 1999. La iglesia del monasterio de Santa Cruz la Real de Segovia a fines del siglo XV: una confluencia de modelos de la arquitectura tardogótica castellana. Anuario de la Universidad Internacional SEK 5: 77-98.

Heyman, J. 1995. Teoría historia y restauración de estructuras de fábrica. Madrid: Instituto Juan de Herrera.

Heyman, J. 1999. El esqueleto de piedra: mecánica de la arquitectura de fábrica. Madrid: Instituto Juan de Herrera.

Heyman, J. 2004. Análisis de estructuras. Un estudio histórico. Madrid: Instituto Juan de Herrera.

Marías, F. 1986. La arquitectura del Renacimiento en Toledo (1541-1631). Madrid: CSIC-CSIC Press.

Palladio, A. 1570. I quattro libri dell'architettur.

Sanjurjo, A. 2007. El caracol de Mallorca en los tratados de cantería españoles de la edad moderna. Quinto Congreso Nacional de Historia de la Construcción. Burgos: Instituto Juan de Herrera

Sanjurjo, A. 2013. Experimentación geométrica y constructiva en piedra: algunos casos especiales de escaleras de caracol. Informes de la Construcción 65 nextra-2:35-48 